\title{
Sol-gel synthesis and structural characterization of band gap engineered ferroelectric perovskite oxide potassium sodium barium nickel niobate
}

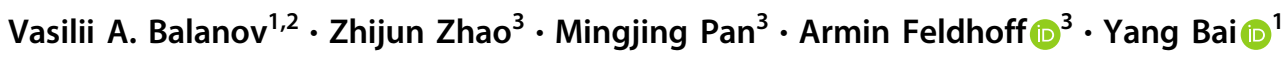

Received: 20 April 2020 / Accepted: 14 July 2020 / Published online: 24 July 2020

(c) The Author(s) 2020

\begin{abstract}
Ferroelectric materials with engineered thus visible-range optical band gaps are increasingly researched in recent years, triggering potentially new applications in solar cells, opto-ferroelectric devices, multifunctional sensors, and multisource energy harvesters. To date, most band gap engineered ferroelectrics have been discovered in form of ceramics fabricated via the solidstate route. Like other functional counterparts further research of these materials into nanoscale developments, e.g., nanocomposites and thin films, demands nanofabrication methods to be investigated. An emerging band gap engineered ferroelectric composition, $(\mathrm{K}, \mathrm{Na}, \mathrm{Ba})(\mathrm{Ni}, \mathrm{Nb}) \mathrm{O}_{3-\delta}(\mathrm{KNBNNO})$, discovered with solid-state route has allured research for novel applications as mentioned above. However, its nanofabrication via wet chemical routes has rarely been reported. In this paper, sol-gel method is used to fabricate KNBNNO nanoparticles. The developed method can successfully form the target perovskite phases, and is able to reduce the particle size from 300 to $400 \mathrm{~nm}$ made via the solid-state reaction to about $100 \mathrm{~nm}$. In addition, the distributed particle size in the synthesized solutions averages at 4-6 nm, making the method suitable for potential thin film fabrication. Therefore, this paper offers a nanofabrication option to the emerging KNBNNO for prospective nanoscale research.
\end{abstract}

\section{Graphical Abstract}

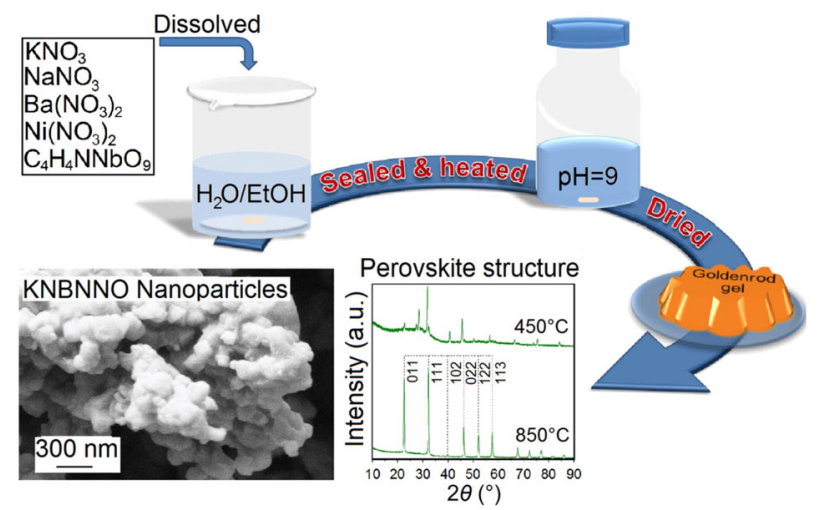

These authors contributed equally: Vasilii A. Balanov, Zhijun Zhao

Armin Feldhoff

armin.feldhoff@pci.uni-hannover.de

$\triangle$ Yang Bai

yang.bai@oulu.fi

1 Microelectronics Research Unit, Faculty of Information Technology and Electrical Engineering, University of Oulu, 90014 Oulu, Finland
2 Solution Chemistry of Advanced Materials and Technology Laboratory, ITMO University, 197101 Saint-Petersburg, Russian Federation

3 Institute of Physical Chemistry and Electrochemistry, Leibniz University Hannover, Callinstrasse 3A, 30167 Hannover, Germany 
Keywords Sol-gel $\cdot$ Photo-ferroelectric $\cdot$ Nanoparticle $\cdot \mathrm{KNBNNO} \cdot \mathrm{KNN}-\mathrm{BNNO} \cdot$ Lead-free

\section{Highlights}

- A sol-gel method for KNBNNO nanoparticles of orthorhombic perovskites from nitrates.

- Particle sizes of 4-6 nm and $~ 100 \mathrm{~nm}$ for synthesized sols and calcined powders, respectively.

- Effect of band gap reduction in Ni-doped particles characterized.

\section{Introduction}

Conventional ferroelectrics with perovskite structures, represented by PZT $\left(\mathrm{Pb}(\mathrm{Zr}, \mathrm{Ti}) \mathrm{O}_{3}\right)$ and $\mathrm{BT}\left(\mathrm{BaTiO}_{3}\right)$ families, are widely used as sensors, actuators, transducers, and energy harvesters thanks to their highly tunable ferroelectricity, which thus gives them excellent piezoelectric and pyroelectric properties [1]. These conventional ferroelectrics normally exhibit optical band gaps beyond the photon energy of visible light [2,3]. For instance, $\mathrm{BiFeO}_{3}$ is one of those with reasonably good ferroelectricity but with a band gap of $2.7 \mathrm{eV}$, corresponding to the photon energy of violet light at the edge of the visible range [4]. The band gap had not been an important parameter for ferroelectrics until they started to be increasingly researched for photovoltaic and optoelectric effects in the recent decade [2,3]. Ferroelectrics like PZT and BT have been found to be able to exhibit photovoltaic effect as early as in the 1960s [5]. Fundamentally different from the working mechanism of conventional semiconductor photovoltaics, ferroelectric photovoltaic materials rely on the built-in electric field generated by spontaneous polarization to separate photoinduced charge carriers [6]. However, the wide band gaps had limited early stage research of the ferroelectric photovoltaic effect to fundamental studies thus little potential of practical use had been realized. Such a judgment has been revised when a ferroelectric, $(\mathrm{K}, \mathrm{Ba})(\mathrm{Ni}, \mathrm{Nb}) \mathrm{O}_{3-\delta}$, reportedly possessed a band gap as narrow as $1.1 \mathrm{eV}$ (same to that of $\mathrm{Si}$, one of the mostly used photovoltaic material) [7]. It is believed that the $\mathrm{Ni}^{2+}$ ion-O vacancy combinations can ease the charge transfer from the $\mathrm{O} 2 p$ states at the maximum level of the valance band to the $\mathrm{Nb} 4 d$ states at the minimum level of the conduction band, compared to the parental composition $\left(\mathrm{KNbO}_{3}\right)$ showing a wide band gap of nearly $4 \mathrm{eV}[7,8]$.

Supported by the same mechanism, another ferroelectric perovskite, $(\mathrm{K}, \mathrm{Na}, \mathrm{Ba})(\mathrm{Ni}, \mathrm{Nb}) \mathrm{O}_{3-\delta}(\mathrm{KNBNNO})$ [9], has been developed from its parental composition $(\mathrm{K}, \mathrm{Na}) \mathrm{NbO}_{3}$ $(\mathrm{KNN})$, which is widely used as a $\mathrm{Pb}$-free, environmentally friendly ferroelectric and piezoelectric ceramic compound [10-12]. KNBNNO shows a comparably narrow band gap of $1.6 \mathrm{eV}$ to that of the above mentioned $(\mathrm{K}, \mathrm{Ba})(\mathrm{Ni}, \mathrm{Nb}) \mathrm{O}_{3-\delta}$ with additional benefits of uncompromised piezoelectric and pyroelectric properties $[8,9]$. It is known that the introduction of $\mathrm{Ni}^{2+}$ ions and $\mathrm{O}$ vacancies is likely to degrade these properties [8]. The co-existence of a narrow band gap and reasonably good piezoelectric and pyroelectric properties has made KNBNNO an ideal candidate not only for visible light absorbers, but also for multifunctional sensors and multisource energy harvesters $[2,9,13,14]$.

KNBNNO can be synthesized via solid-state route, which however, results in a large particle size (mean value of 300-400 nm) [9]. Like many compositions, macroscopic ceramic powders and their nanoparticles are equally important for both research and applications as the latter help to fabricate nanoscale materials, which may unveil nanoscale insights and boost material properties/capabilities $[1,15]$. As KNBNNO is a very recently discovered composition, its nanofabrication methods have rarely been investigated. Its parental composition, $(\mathrm{K}, \mathrm{Na}) \mathrm{NbO}_{3}$, has been successfully fabricated via a sol-gel method using acetates of $\mathrm{K}, \mathrm{Na}$, and $\mathrm{Nb}$ in acetic acid and 2methoxyethanol solvents which are toxic and not environmentally friendly [16-19]. Following a similar sol-gel route with acetates of $\mathrm{K}, \mathrm{Na}, \mathrm{Ba}, \mathrm{Ni}$ and $\mathrm{Nb}, \mathrm{KNBNNO}$ has also been fabricated [20]. For convenience of expression, $\mathrm{KNBNNO}$ is presented by $\mathrm{KNN}-x \mathrm{BNNO}-\left[\left(\mathrm{K}_{0.5} \mathrm{Na}_{0.5}\right)\right.$ $\left.\mathrm{NbO}_{3}\right]_{1-x}-\left[\mathrm{Ba}\left(\mathrm{Ni}_{0.5} \mathrm{Nb}_{0.5}\right) \mathrm{O}_{2.75}\right]_{x}$-instead hereinafter. Although the nanofabrication of $\mathrm{KNN}-x \mathrm{BNNO}$ is feasible in acid and organic environment, the use of neutral or basic solvent has not been reported, especially for water as an environmentally friendly solvent. Meanwhile, in the only literature of the sol-gel synthesis of $\mathrm{KNN}-x \mathrm{BNNO}$, the concentration of BNNO is relatively high $(x=0.1-0.3)$ [20]. However, it has been proved that a small amount of Ni-doping (e.g., $x=0.02$ ) should be enough to significantly reduce the band gap whilst retaining good ferroelectric, piezoelectric, and pyroelectric properties [9]. An increase of BNNO concentration deteriorates these properties without further changing the band gap significantly [9].

Therefore, this paper dedicates to address these issues. Nanoparticles of KNN- $x$ BNNO with compositional parameter $x=0.02-0.1$ are fabricated via the sol-gel route using nitrates of $\mathrm{K}, \mathrm{Na}$, and $\mathrm{Ni}$ and ammonium niobate oxalate in water and ethanol. Average particle sizes of $4-6 \mathrm{~nm}$ and 
Fig. 1 Sol-gel synthetic procedures for $\mathrm{KNN}-x \mathrm{BNNO}$ developed in this paper

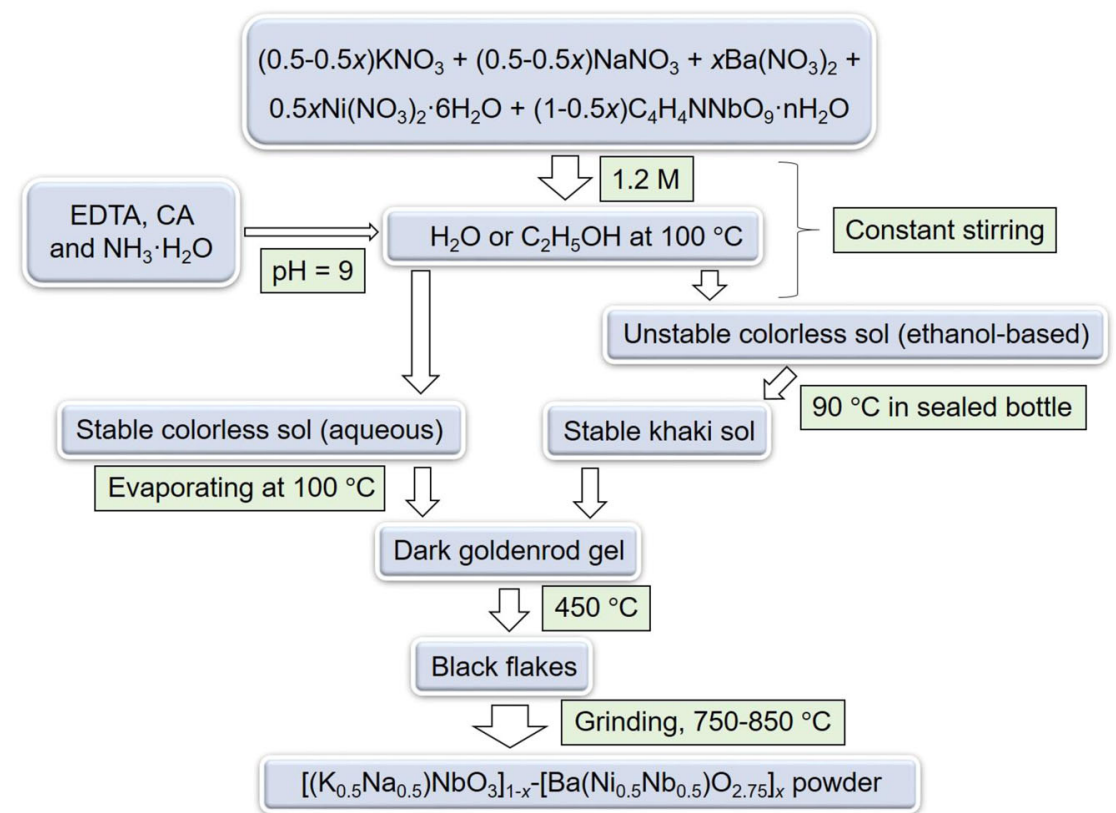

$\sim 100 \mathrm{~nm}$ are achieved for the synthesized $\mathrm{KNN}-x \mathrm{BNNO}$ solutions and powders, respectively. Meanwhile, pure perovskite phases are obtained, proving the success and feasibility of the reported method in this paper.

\section{Experimental}

All chemicals used in this paper were purchased from Sigma Aldrich. Potassium nitrate $\left(\mathrm{KNO}_{3}, 99.5 \%\right)$, sodium nitrate $\left(\mathrm{NaNO}_{3}, 99.5 \%\right)$, barium nitrate $\left(\mathrm{Ba}\left(\mathrm{NO}_{3}\right)_{2},>99 \%\right)$, nickel (II) nitrate hexahydrate $\left(\mathrm{Ni}\left(\mathrm{NO}_{3}\right)_{2} \cdot 6 \mathrm{H}_{2} \mathrm{O},>99 \%\right)$ and ammonium niobate (V) oxalate hydrate $\left(\mathrm{C}_{4} \mathrm{H}_{4} \mathrm{NNbO}_{9} \cdot n \mathrm{H}_{2} \mathrm{O}, 99.99 \%\right)$ were used as reactants. EDTA (ethylenediaminetetraacetic acid, >99.4\%) and CA (citric acid, $>99.5 \%$ ) were used as chelating agents. Figure 1 illustrates the synthetic procedure. First, the reactants with the correct stoichiometry were dissolved in de-ionized water or ethanol (with concentration of the solvent $1.2 \mathrm{M}$ ) at $100{ }^{\circ} \mathrm{C}$ and constantly stirred until a transparent, colorless solution was obtained. Subsequently, EDTA and CA were added into the solution with molecular ratio of EDTA:CA: $M e=1: 2: 1$, where $M e$ is the total metal ions. The $\mathrm{pH}$ value of the solution was adjusted to 9 with ammonia solution $\left(\mathrm{NH}_{3} \cdot \mathrm{H}_{2} \mathrm{O}, 27-30 \mathrm{wt} \%, \mathrm{CO}_{2}\right.$ traces $\left.<0.002 \%\right)$. These steps were carried out in capped and sealed bottles.

It should be noted that after the above mentioned procedures, the aqueous solution was stable without precipitation after the stirring was stopped. The ethanol-based solution precipitated quickly in a few hours even if being constantly stirred. This solution could be stabilized through heat treatment at $90^{\circ} \mathrm{C}$ in a sealed bottle placed in an oven for several days. Once the solution was stabilized, its color changed to khaki.

The stabilized solutions were transferred into an evaporation bowl, dried at $100{ }^{\circ} \mathrm{C}$ in an oven until dark goldenrod gels appeared, and finally fired at $450{ }^{\circ} \mathrm{C}$ with a heating rate of $5^{\circ} \mathrm{C} / \mathrm{min}$ until the gels turned to black flakes. The final products were obtained after grinding the flakes in mortar and calcining them at $750-850^{\circ} \mathrm{C}$. Thermal changes in the transitions from the dried gels to calcined powders were studied by carrying out DSC (differential scanning calorimetry) and TG (thermogravimetric) analyses (STA449, NETZSCH, Germany) in the temperature range of $25-900{ }^{\circ} \mathrm{C}$ with a heating rate of $3{ }^{\circ} \mathrm{C} / \mathrm{min}$. The phases of the synthesized powders were identified with XRD (X-ray diffractometer, D8 Discover, Bruker, Germany, step size $0.05^{\circ}$, scan speed $1 \mathrm{~s} / \mathrm{step}$; and PW 1800, Philips, Netherlands, step size $0.02^{\circ}$, scan speed $2 \mathrm{~s} / \mathrm{step}$ ) (with $\mathrm{Cu} \mathrm{K} \alpha$ radiation at $40 \mathrm{kV}$ and $40 \mathrm{~mA}$ ). FE-SEM (field-emission scanning electron microscope, Sigma, Zeiss, Germany) was used to examine the morphology of the powders. Another FE-SEM (ULTRA plus, Zeiss, Germany) equipped with EDXS (energy dispersive X-ray spectrometer) was used for elemental analyses. The particle size distribution was measured both in SEM micrographs and by DLS (dynamic light scattering, Compact-Z, Photocor, Russian Federation). The zeta potential was measured with Zetasizer Nano (Malvern Instruments Ltd, UK). This Zetasizer was also used to double check thus confirm the particle sizes. Transmittance of the calcined powders was measured with a UV-Vis-NIR spectrophotometer (Cary 500 Scan, Varian, USA). 


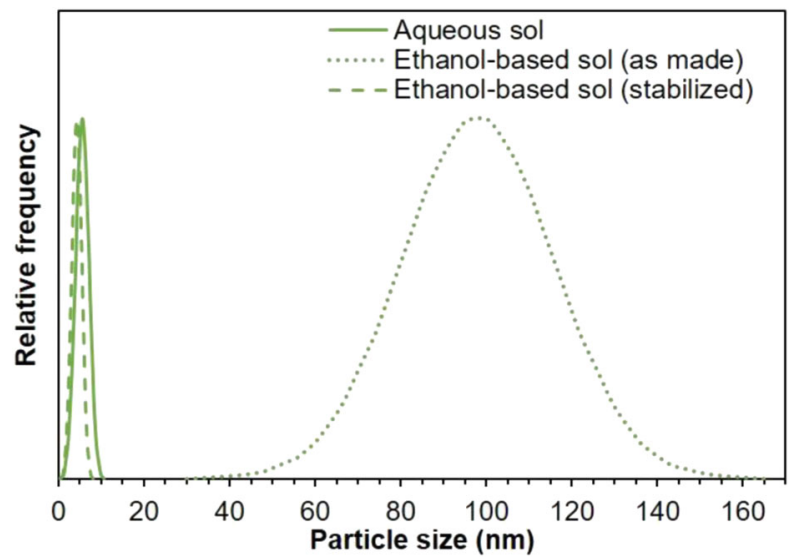

Fig. 2 Particle size distributions of $\mathrm{KNN}-x \mathrm{BNNO}(x=0.02)$ in aqueous and ethanol-based sols fitted with log-normal distribution

Table 1 Mean particle sizes and zeta potentials (measured at $\mathrm{pH}=9$ ) of the aqueous and ethanol-based sols $(x=0.02)$

\begin{tabular}{lcl}
\hline & $\begin{array}{l}\text { Mean particle } \\
\text { size }(\mathrm{nm})\end{array}$ & $\begin{array}{l}\text { Zeta potential } \\
(\mathrm{mV})\end{array}$ \\
\hline Aqueous & $5.6 \pm 0.1$ & $-16 \pm 3$ \\
Ethanol based (as made) & $98 \pm 0.1$ & $-33 \pm 15$ \\
Ethanol based (stabilized) & $4.3 \pm 0.1$ & $-34 \pm 3$ \\
\hline
\end{tabular}

\section{Results and discussions}

Figure 2 shows the mean hydrodynamic diameter of the colloidal particles in the aqueous and ethanol-based sols (as made and after being stabilized by heat treatment as mentioned above) measured from DLS. Table 1 compares their mean particle size values and zeta potentials. The particles in the aqueous and stabilized ethanol-based sols were monodisperse with narrow size distributions between 0 and $11 \mathrm{~nm}$ (aqueous) $/ 10 \mathrm{~nm}$ (stabilized ethanol based), and mean sizes of $5.6 \mathrm{~nm}$ (aqueous) $/ 4.3 \mathrm{~nm}$ (stabilized ethanol based) in diameter. This makes both the sols suitable precursors for potential fabrication of thin films using methods like spin coating [20]. Thickness of the films is tunable in a broad range with fine interval thanks to the minimum achievable single-layer thickness, which is largely determined by the particle size. The particles in the as made ethanol-based sol demonstrated a broad size distribution $(30-170 \mathrm{~nm})$ with a mean value of $98 \mathrm{~nm}$ in diameter. This implies that the reactants and nanoparticles were more likely to form clusters in the ethanol environment, and, this explains that the as made ethanol-based sol tended to precipitate rapidly as presented above. Although the as made and stabilized ethanol-based sols showed similar average zeta potentials, that of the as made ethanol-based sol varied significantly as indicated by its deviation (Table 1). If taking the largest deviation into account, the zeta potential of the as made ethanol-based sol could reach a value as weak as $-18 \mathrm{mV}(-33+15 \mathrm{mV})$ (Table 1). This may be an indicative factor responsible for the instability of the as made ethanol-based sol. A part of the particles associated with relatively weak zeta potentials (e.g., $-18 \mathrm{mV}$ ) may aggregate first due to lack of electrostatic repulsion between particles. The aggregated particles increase in size, thus the rest of the smaller particles need a stronger repulsion to confer stability, lifting the lower limit of zeta potential for resisting aggregation. This may further cause a domino effect, leading to a fast precipitation from the macroscopic view. In comparison, the deviations of zeta potentials for the aqueous and stabilized ethanol-based sols were much smaller, which may help to eliminate the triggering effect as may have happened in the as made ethanol-based sol. Table 1 also provides a hint that the electrostatic repulsion needed to stabilize the aqueous sol can be about only half of that needed to stabilize the ethanol-based sol. This may be attributed to the difference between the features of water and ethanol molecules where water is more chemically stable while ethanol may produce hydroxide $\left(\mathrm{OH}^{-}\right)$that can combine with the particles containing alkaline elements or can break the $\mathrm{pH}$ balance.

Figure 3 shows the XRD patterns of the KNN $-x \mathrm{BNNO}$ powders (after calcination at $750{ }^{\circ} \mathrm{C}$ ) with $x=0,0.02,0.04$, $0.06,0.08$, and 0.1 , all made from the aqueous sols. It can be seen that all the powders formed orthorhombic perovskite phases, consistent with its parental composition $(x=0)$ with a space group of Amm2 [9, 21]. Additional reflections at about 37 and $43^{\circ}$ indicate the presence of excess $\mathrm{NiO}$ that did not diffuse into the solid solutions $[7,9,22]$. It should be noted that the intensity of the $\mathrm{NiO}$ reflections in the $x=0.02$ powder shown in Fig. 3 is hardly visible, indicating a relatively complete diffusion. The perovskite reflections for all the samples broadened with increase of the $x$ value, implying a decreased crystallinity. In the meantime, the intensity of $\mathrm{NiO}$ reflections also increased with increased value of the compositional parameter $x$. According to the Scherrer equation [23], the broadened reflections corresponded to decreased crystallite size. From this perspective, the crystallite size of the $\mathrm{KNN}-$ $x$ BNNO powders decreased with increased value of $x$. In addition, reflections of 111,022/200, and 122/211 at about $32^{\circ}, 46^{\circ}$, and $52^{\circ}$, respectively, shifted toward lower angles with increased value of $x$ (Fig. 3). In KNN-xBNNO, two different transition metal cations were located at the B-site. The $\mathrm{Nb}^{5+}$ drives ferroelectricity together with A-site cations whilst $\mathrm{Ni}^{2+}$ reduces the band gap [7, 24]. An off-center lattice distortion and polarization in the classic ferroelectric perovskite $\mathrm{KNbO}_{3}$ caused by $\mathrm{Na}^{+}$-doping [10] provides a favorable condition to introduce a combination of $\mathrm{Ni}^{2+}$ and 


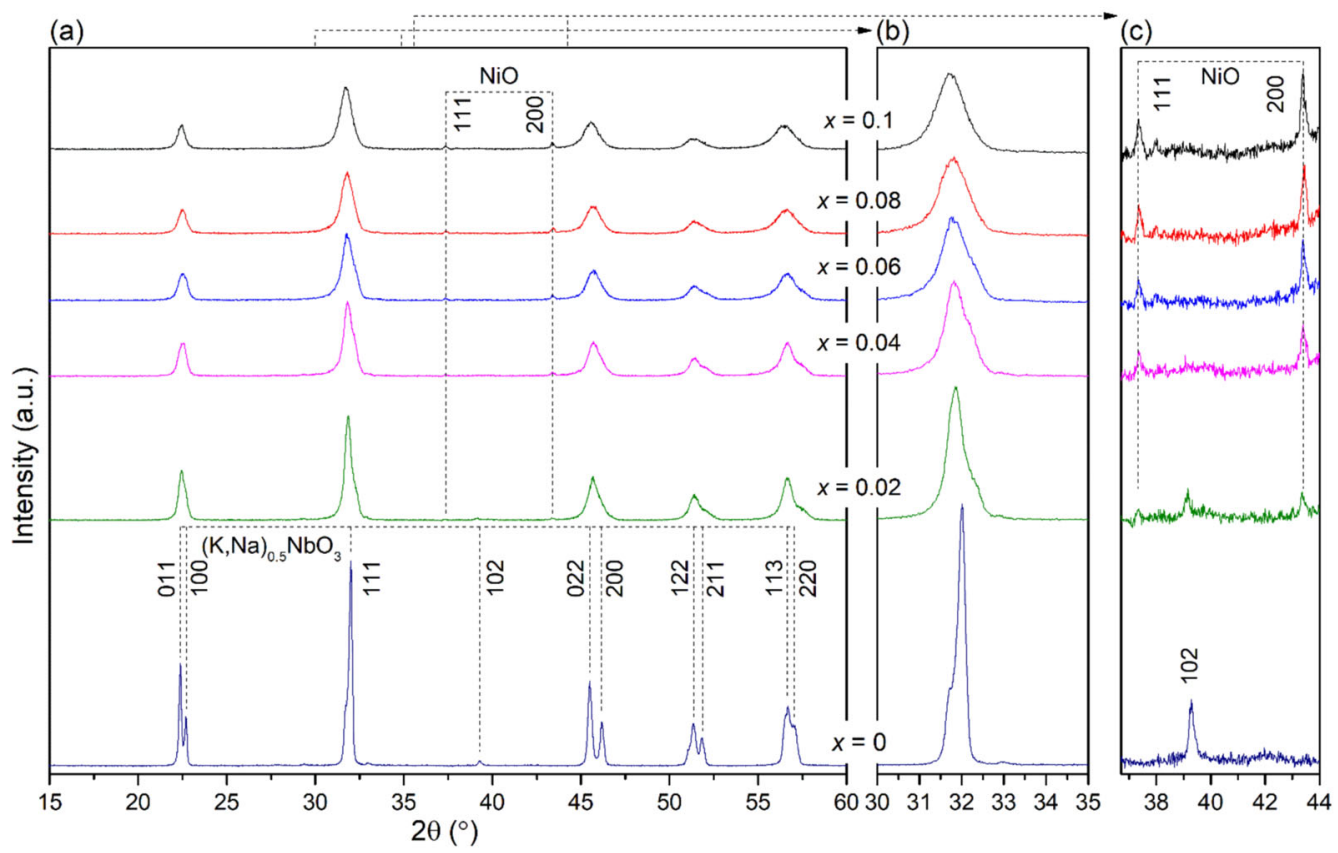

Fig. 3 XRD patterns of $\mathrm{KNN}-x \mathrm{BNNO}$ powders made from the aqueous sols with different $x$ values after being calcined at $750{ }^{\circ} \mathrm{C}:$ a full angular range and $(\mathbf{b}, \mathbf{c})$ close-ups

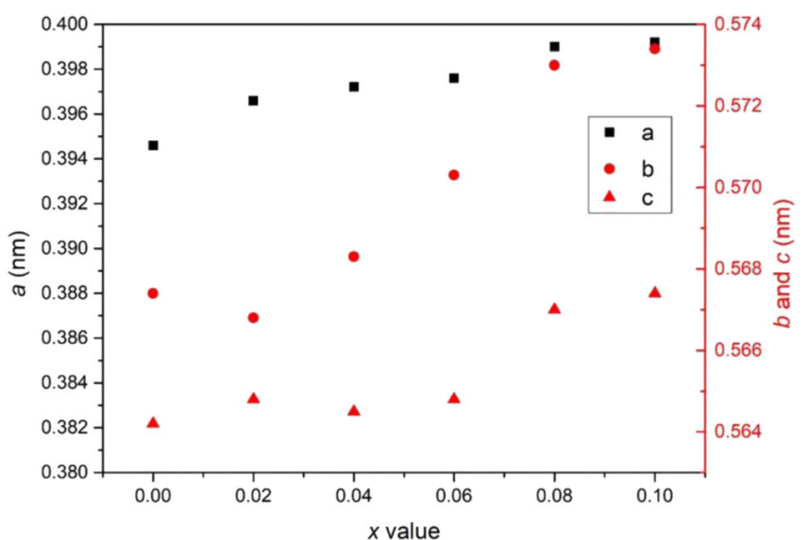

Fig. 4 Orthorhombic lattice parameters $a, b$ and $c$ (estimated by Pawley fit) of $\mathrm{KNN}-x \mathrm{BNNO}$ powders made from the aqueous sols with different $x$ values after being calcined at $750^{\circ} \mathrm{C}$

$\mathrm{O}$ vacancy, which is responsible for the rise of electronic states in the gap of the $\mathrm{KNbO}_{3}[7,9,22]$. In this principle, the lattice parameters of $\mathrm{KNN}-x \mathrm{BNNO}$ increased with increased $x$ value in presence of $\mathrm{Ni}^{2+}$ ions, which has a larger ionic radius of $69 \mathrm{pm}$ compared to $\mathrm{Nb}^{5+}$ (64 pm). This is the reason that the above mentioned reflections shifted to smaller angles (implying increasing lattice parameters) and at the same time broadened (implying smaller crystallite sizes).

Figure 4 shows the evolution of lattice parameters of the $\mathrm{KNN}-x \mathrm{BNNO}$ calcined powders corresponding to the XRD patterns in Fig. 3. It can be seen that the incorporation of $\mathrm{Ni}$ induced the most obvious change on lattice parameter $b$. All

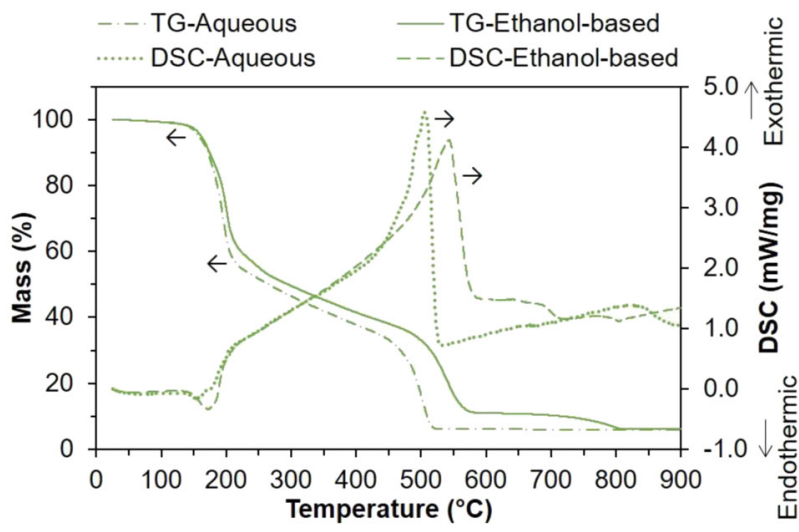

Fig. 5 Results of TG and DSC analyses for the dried gels of KNN$x$ BNNO made from the aqueous and ethanol-based sols with $x=0.02$

lattice parameters as well as the trend of their evolutions with the $\mathrm{Ni}$ concentration are in good agreement with results obtained on sintered ceramics, which were made via solid-state route [9]. This indicates successful fabrications using the sol-gel method in this work. The intensity of the 102 reflection decreased with the increased value of $x$, which is a consistent observation to that of ceramic powders made via solid-state route [22]. The decreasing intensity of the 102 reflection may be caused by the change of particle orientation or due to the structure factor vanished thus prohibited diffraction of the 102 reflections.

Similar with ceramic powders made from solid-state route, calcination temperature also plays an important role in the sol-gel process chosen for this work. Figure 5 shows 
the TG and DSC curves measured with the dried goldenrod gels from both the aqueous and ethanol-based sols $(x=$ $0.02)$. For both gels, the first significant weight loss $(\sim 40 \%)$ was observed in the temperature range of $150-200^{\circ} \mathrm{C}$. This should be assigned to the decomposition and volatilization of organic compounds such as EDTA and CA $\left(\mathrm{NH}_{3} \cdot \mathrm{H}_{2} \mathrm{O}\right.$ should have been removed during the drying process), which is supported by the endothermic behaviors on the DSC curves. The loss of organic compounds was followed by chemical reactions among the reactants and crystallizations of the particles. The weight losses observed at $>200{ }^{\circ} \mathrm{C}$ should be resulted from the volatilization of $\mathrm{N}$-containing compounds produced during the reactions as well as possible water of crystallization. For the aqueous sol, these procedures seemed to complete at $520^{\circ} \mathrm{C}$ where both the weight loss on the TG curve and the major exothermic behavior on the DSC curve ended. In the temperature range of $800-850{ }^{\circ} \mathrm{C}$, the DSC curve of the aqueous sol showed another smaller exothermic peak but no further weight loss was observed on the TG curve. This implies that an abnormal grain growth might happen at high temperatures. In comparison, for the ethanol-based sol the reactions did not finish until $800^{\circ} \mathrm{C}$ with the evidences of consecutive weight losses on the TG curve and several exothermic peaks on the DSC curve in the temperature range of $200-800^{\circ} \mathrm{C}$. For this reason, the calcination temperature of the flakes made from the ethanol-based sols was chosen to be $850^{\circ} \mathrm{C}$ to ensure complete chemical reaction and phase formation. In principle, $550{ }^{\circ} \mathrm{C}$ should be enough for the flakes made from the aqueous sols. However, in order to compare with the powders made from the ethanolbased sols, similar calcination temperatures were selected, i.e., $750-800{ }^{\circ} \mathrm{C}$ for the aqueous sols. The reason here was that a much lower calcination temperature (e.g., $550^{\circ} \mathrm{C}$ ) may suppress grain growth, generating misleading information about the grain and particle sizes, while a higher temperature (e.g., $850^{\circ} \mathrm{C}$ ) may lead to abnormal grain growth beyond the nanoscale. In addition, $450{ }^{\circ} \mathrm{C}$ was chosen to be the pyrolysis temperature for both the aqueous and ethanol-based sols because this was after the organic compound removal and before the major inorganic reaction (the highest exothermic peaks on the DSC curves) happened.

Figure 6 compares the XRD patterns and SEM micrographs of the $x=0.02$ sample (made from the ethanol-based sol) measured after heat treatment at $450{ }^{\circ} \mathrm{C}$ (from gel to flake) and $850^{\circ} \mathrm{C}$ (from flake to powder). As explained above with Fig. 5, the gel-flake evolution mainly involved the decompositions and volatilizations of organic compounds. As shown in Fig. 6, the black flakes already started to show some preliminary characteristics of the target perovskite structure, with most of the major reflections corresponding to the $850^{\circ} \mathrm{C}$ calcined powder. However, it is

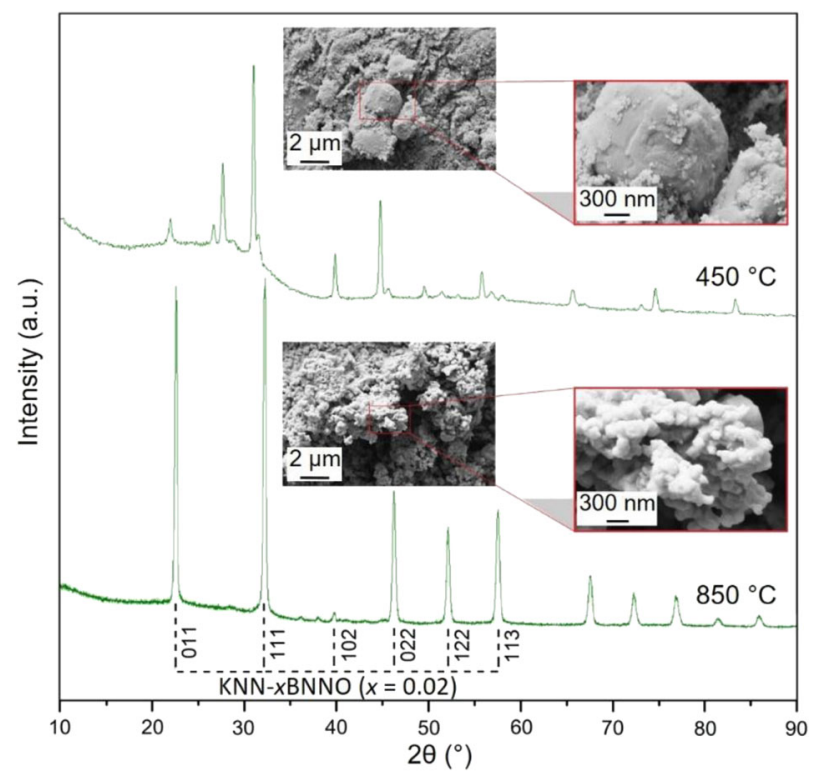

Fig. 6 XRD patterns and SEM micrographs of $\mathrm{KNN}-x \mathrm{BNNO}(x=$ 0.02 ) made from the ethanol-based sol after being fired at $450{ }^{\circ} \mathrm{C}$ and calcined at $850^{\circ} \mathrm{C}$

obvious that the reaction was not complete at $450{ }^{\circ} \mathrm{C}$. A significant amount of residual carbon in flakes is illustrated in Fig. 7a. The carbon source here was likely to be the residual carbon from the ethanol which formed carbon crosslinks between molecules. The residual carbon as well as the accumulation spots of certain elements like $\mathrm{K}$ explains the incomplete formation of the perovskite phase as indicated by XRD patterns in Fig. 6, i.e., additional reflections to the marked ones for the perovskite phase. This is supported by the evidence that on the DSC curve of the ethanol-based sol (Fig. 5) there were several exothermic peaks associated with consecutive weight losses on the corresponding TG curve at $>450{ }^{\circ} \mathrm{C}$ until $800^{\circ} \mathrm{C}$, i.e., the transformation from flake to powder, indicating reactions of the residual $\mathrm{K}$ with the perovskite compound and phase formation. The incomplete phase formation at $450{ }^{\circ} \mathrm{C}$ may have been caused by residual carbon crosslinks prohibiting crystallization and/or may be because $\mathrm{K}$ needed a higher thermal energy to activate its reaction/diffusion in the structure. The subsequent calcination at a temperature of $850{ }^{\circ} \mathrm{C}$ successfully burned the carbon off (Fig. $7 \mathrm{~b}$ ), inducing a homogenous distribution of the elements. Large agglomerates of several microns were found with flakes, while for calcined powders the particle size decreased by an order of magnitude to $\sim 100 \mathrm{~nm}$ (Figs. 6 and 10b). The large agglomerates were formed because of high surface energy yielded by nanoparticles in the procedure of sol-gel flake. Meanwhile, the large-sized particles on the black flakes were also likely due to the crosslinks formed around carbon atoms. Adding proper dispersant is a usual way to minimize the formation of agglomerates of nanoparticles, but this was 
Fig. 7 EDXS analysis results of KNN- $x$ BNNO $(x=0.02)$ made from the ethanol-based sol a after being fired at $450{ }^{\circ} \mathrm{C}$ and $\mathbf{b}$ calcined at $850^{\circ} \mathrm{C}$
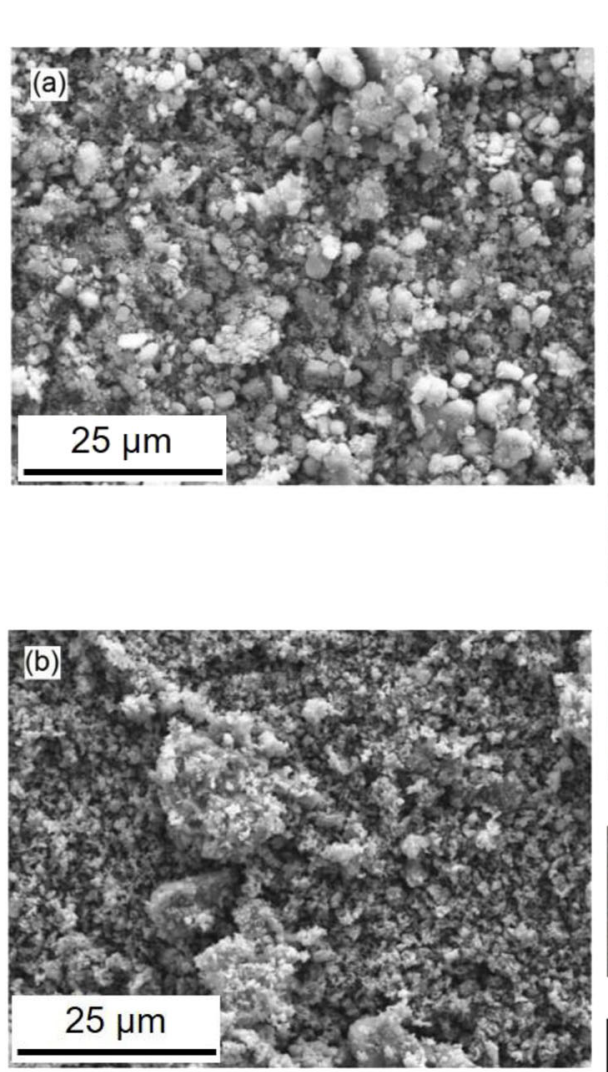

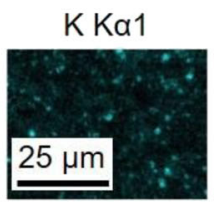

Ni Ka1

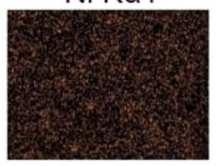

C Ka1

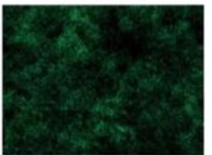

$\mathrm{KKa} 1$
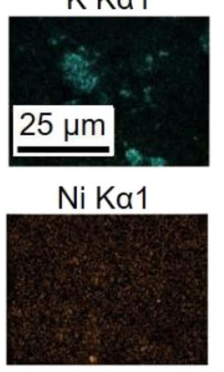

C Ka1

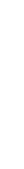

$\mathrm{Na} \mathrm{Ka1}$

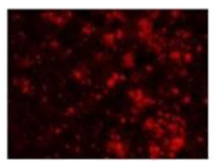

$\mathrm{Nb} \operatorname{La} 1$

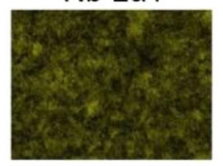

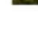

Ba La1

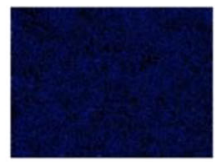

$\mathrm{O}$ Ka1

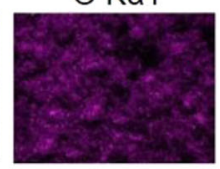

$\mathrm{Na} \mathrm{Ka1}$

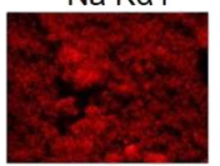

Nb La1

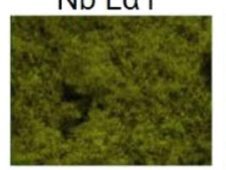

3

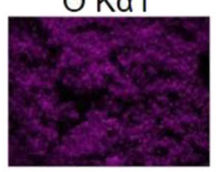

$\mathrm{O} \mathrm{Ka1}$

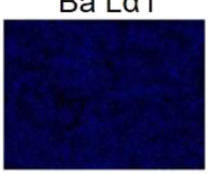

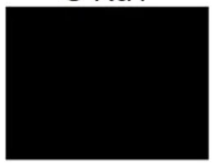

not considered crucial in this work as the particle size was greatly reduced in the final product (the calcined powder). During the calcination, carbon was burnt off and thus the possible carbon crosslinks were destroyed, resulting in large particles and agglomerates breaking in to smaller particles. Compared to the $850^{\circ} \mathrm{C}$ calcined powder, the XRD reflections of the $450{ }^{\circ} \mathrm{C}$ fired flake shifted toward lower angles (Fig. 6). This indicates that the lattice parameters of the flake tend to be larger than those of the powder, possibly due to inter-lattice strains induced by carbon crosslinks stretching the unit cells or the unit cell distortion/expansion caused by defects. For instance, the accumulated $\mathrm{K}$ spots (Fig. 7a) which did not diffuse into the $\mathrm{A}$ site of the $\mathrm{ABO}_{3}$ perovskite unit cell imply a large amount of $\mathrm{K}^{+}$vacancies in the flake, leading to variation of the lattice parameters.

Compared to the pure KNN $(x=0)$, the BNNO doped compositions have a broader window of calcination temperature. It is well known that the calcination and sintering temperature of pure KNN ceramics must be carefully chosen as a lower temperature may lead to incomplete phase formation while a higher temperature (e.g., $>800^{\circ} \mathrm{C}$ ) may cause volatilization of the alkaline elements $[11,21]$. Figure 8 shows the XRD patterns of KNN- $x$ BNNO powders for $x=0$ and $x=0.1$ (made from the aqueous sols) calcined

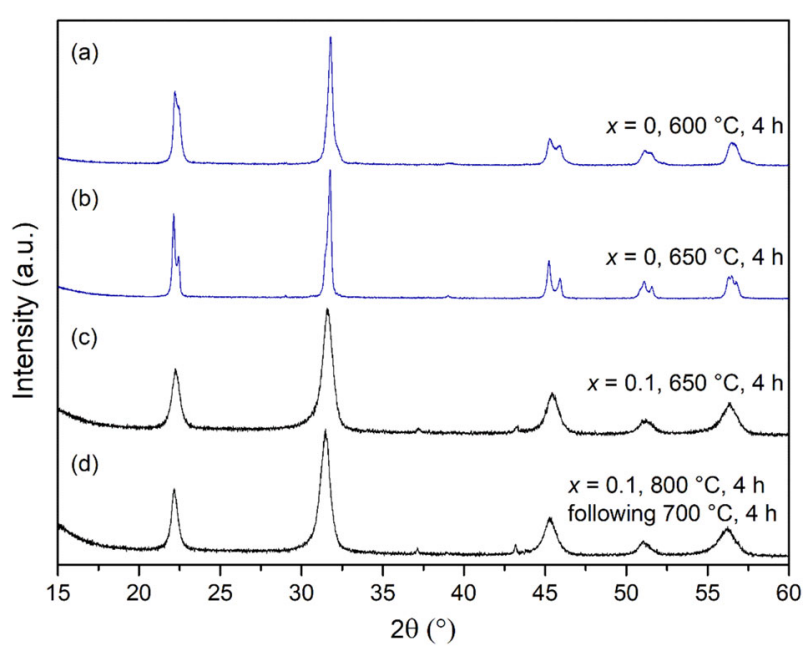

Fig. 8 XRD patterns of $\mathrm{KNN}-x \mathrm{BNNO}$ powders made from the aqueous sols for $x=0$ calcined at a $600^{\circ} \mathrm{C}$ and $\mathbf{b} 650{ }^{\circ} \mathrm{C}$, and $x=0.1$ calcined at c $650{ }^{\circ} \mathrm{C}$ and $\mathbf{d} 700^{\circ} \mathrm{C}$ followed by $800{ }^{\circ} \mathrm{C}$

with different profiles. A better crystallinity was found for pure $\mathrm{KNN}$ when calcined at $650{ }^{\circ} \mathrm{C}$ compared to $600{ }^{\circ} \mathrm{C}$ (Fig. 8a, b) where the reflection splitting can be more clearly recognized at $650{ }^{\circ} \mathrm{C}$. This is consistent with previous experience and the same trend was found on the 
Fig. 9 SEM micrographs of KNN $-x$ BNNO powders made from the aqueous sols and calcined at $750{ }^{\circ} \mathrm{C}$ (a) $x=0$

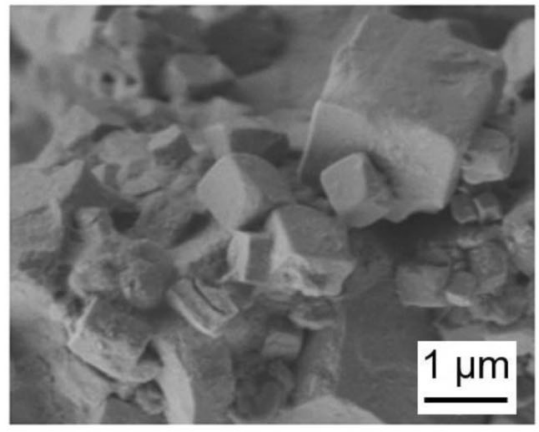

(c) $x=0.04$

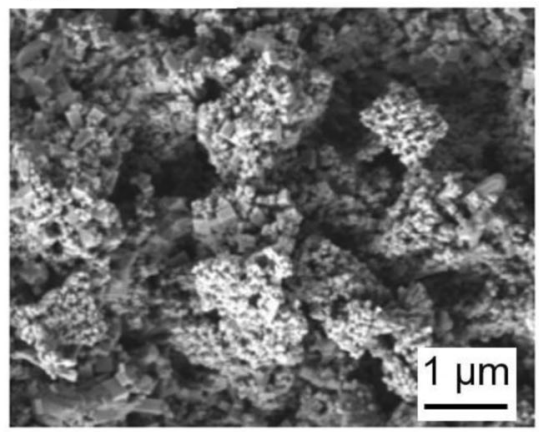

(e) $x=0.08$

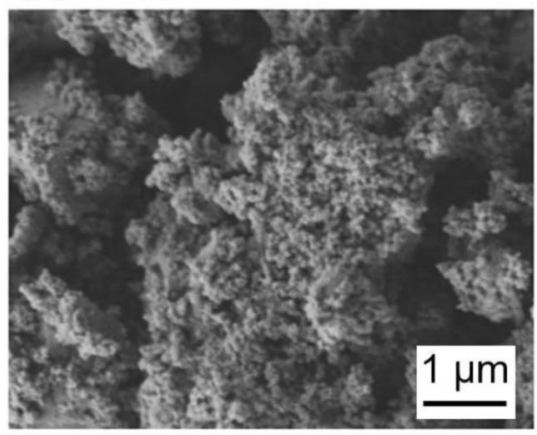

(b) $x=0.02$

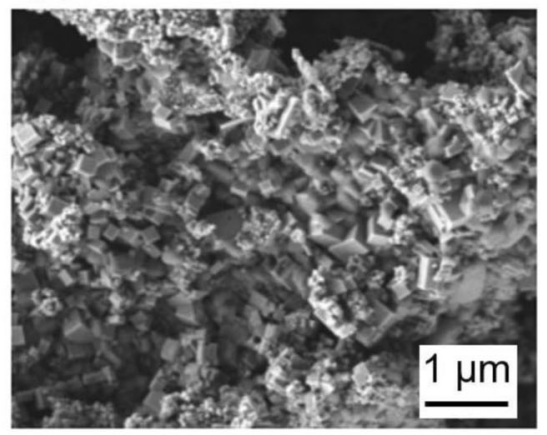

(d) $x=0.06$

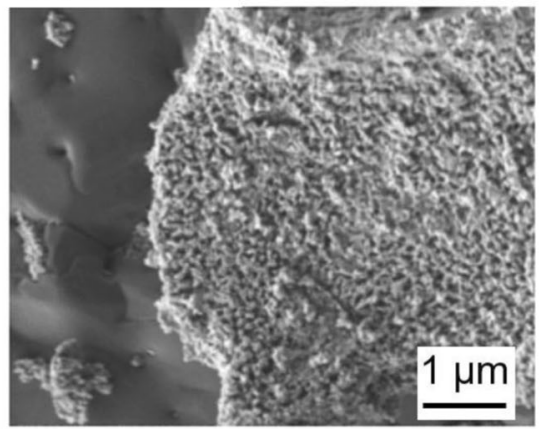

(f) $x=0.1$

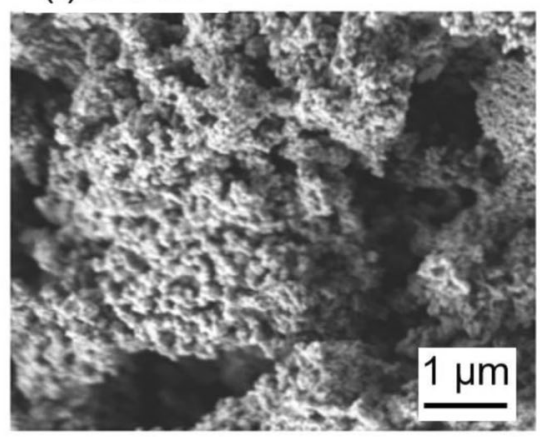

KNN- $x$ BNNO $(x>0)$ samples. In comparison, higher temperature was needed to calcine the $\mathrm{KNN}-x \mathrm{BNNO}(x>0)$ samples. In other words, the doping of BNNO into KNN increased the difficulty of phase formation. This should have brought a disadvantage to the $\mathrm{KNN}-x \mathrm{BNNO}(x>0)$ compositions as higher temperature tends to cause loss of alkaline elements, leading to the stoichiometry shifting away from the designed values. However, alkaline cations seemed to be immobilized inside the lattice of $\mathrm{KNN}-$ $x \mathrm{BNNO}$ thus were more stable than that in pure KNN. This statement was supported by the fact that strong volatilization of potassium hydroxide was detected in the pure $\mathrm{KNN}$ precursor calcined at $850{ }^{\circ} \mathrm{C}$ while it was not observed in $\mathrm{KNN}-x \mathrm{BNNO}(x=0.1)$ calcined at the same temperature $\left(850^{\circ} \mathrm{C}\right)$. This helped to successfully synthesize $\mathrm{KNN}-$ $x \mathrm{BNNO}$ at necessarily higher temperatures to form proper perovskite phases. The evidence can also be seen in Fig. 8c, d where higher calcination temperature did not lead to significant change of reflection positions and shapes representing variations of lattice parameters. This is consistent with the observations in corresponding ceramics made via the solid-state route [22].

Figure 9 shows the SEM micrographs of the calcined $\mathrm{KNN}-x \mathrm{BNNO}$ powders with different values of $x$ (made from the aqueous sols). Cubic grains were grown in all samples, corresponding to the orthorhombic shape of the perovskite phase. The grains became more homogeneously distributed and more agglomerates were formed with increased value of $x$. To determine the grain sizes, the lengths of 100 grains were measured with the software ImageJ for powders with $x=0,0.02$, and 0.04 . Grain sizes of the other powders were too small $(<70 \mathrm{~nm})$ to be 

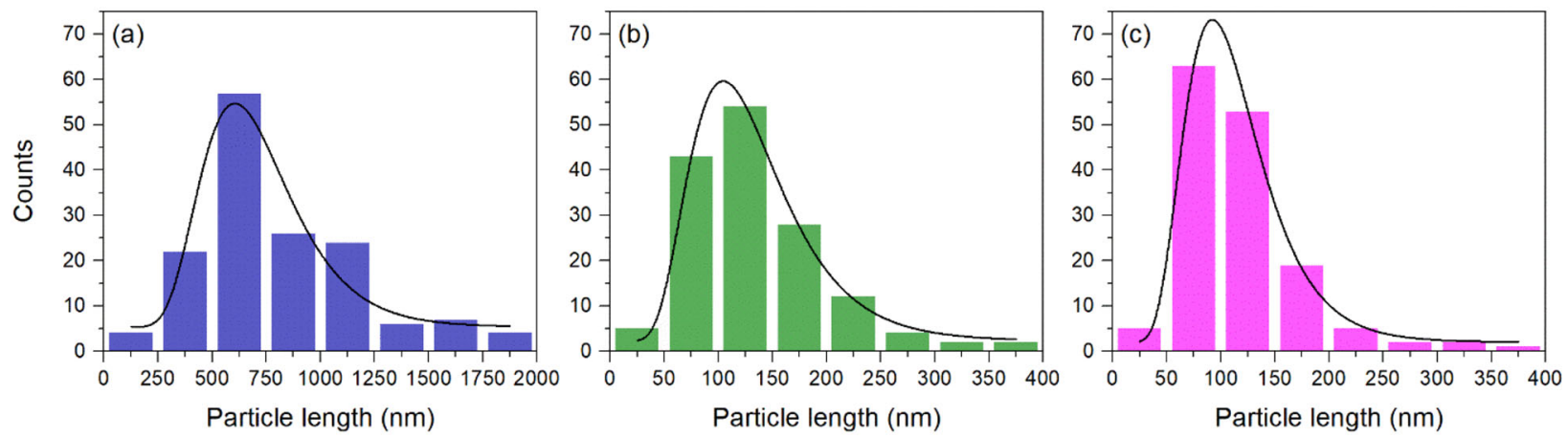

Fig. 10 Particle (grain) size distribution of $\mathrm{KNN}-x \mathrm{BNNO}$ (made from the aqueous sols) $\mathbf{a} x=0, \mathbf{b} x=0.02$, and $\mathbf{c} x=0.04$ powders calcined at $750{ }^{\circ} \mathrm{C}$ calculated from SEM micrographs and with log-normal distribution fitted curves

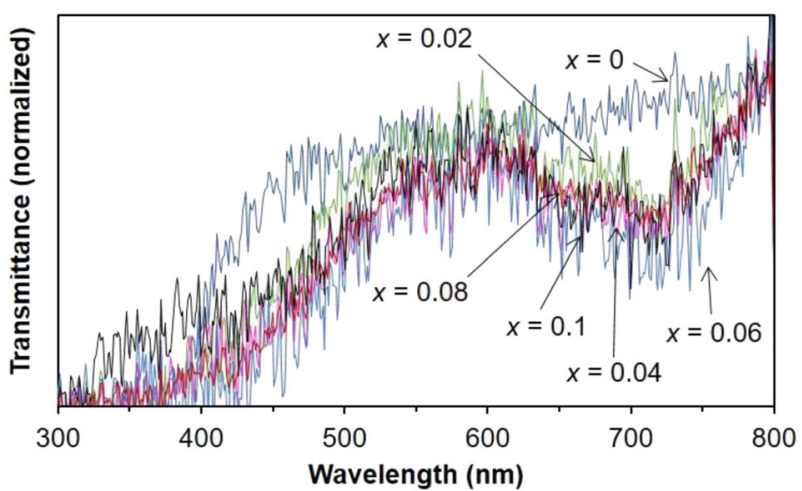

Fig. 11 Dependence of transmittance on wavelength for the KNN$x$ BNNO powders with different $x$ values made from the aqueous sols and calcined at $750^{\circ} \mathrm{C}$

accurately measured. Figure 10 shows the grain length distribution with log-normal distribution fitted curves. The average grain size was $679 \pm 40 \mathrm{~nm}, 123 \pm 2 \mathrm{~nm}$ and $106 \pm$ $1 \mathrm{~nm}$ for the compositions with $x=0,0.02$, and 0.04, respectively. The decreasing trend of particle (grain) size with the increased value of $x$ is consistent with the results expected from the XRD patterns (see discussions related to Fig. 3), which was likely to be due to $\mathrm{Ni}^{2+}-\mathrm{O}$ vacancy defect dipoles acting as centers to suppress grain growth. With the increase of $x$ value, an increasing concentration of the defect dipoles may play a more significant role in grain growth suppression and hence the insufficiently grown, small sized grains looked more homogeneously distributed. The smaller grains were associated with higher surface (grain boundary) energy, leading to more severe agglomeration.

Figure 11 shows the absorption behaviors in the visible light range for $\mathrm{KNN}-x \mathrm{BNNO}$ powders made from the aqueous sols and calcined at $750{ }^{\circ} \mathrm{C}$ with different $x$ values. Compared to the pure $\mathrm{KNN}(x=0)$, all other powders containing $\mathrm{Ni}$ showed an additional absorption edge at the wavelength of about $650-700 \mathrm{~nm}$, corresponding to a photon energy of $1.8-1.9 \mathrm{eV}$. This qualitatively confirms the effect of $\mathrm{Ni}$ doping on band gap reduction, indicating successful fabrications of the $\mathrm{KNN}-x \mathrm{BNNO}$ powders via the sol-gel method.

\section{Conclusions}

Powders of nanoparticles of a band gap engineered ferroelectric perovskite, $\left[\left(\mathrm{K}_{0.5} \mathrm{Na}_{0.5}\right) \mathrm{NbO}_{3}\right]_{1-x}-\left[\mathrm{Ba}\left(\mathrm{Ni}_{0.5} \mathrm{Nb}_{0.5}\right)\right.$ $\left.\mathrm{O}_{2.75}\right]_{x}$ with $x=0-0.1$ have been fabricated via a sol-gel method using nitrates of $\mathrm{K}, \mathrm{Na}, \mathrm{Ni}$, and $\mathrm{Ba}$ and ammonium niobate oxalate hydrate as the reactants, and EDTA and CA as the chelating agents. De-ionized water and ethanol were used as solvents. The solutions give an average particle size of 4-6 nm, which is suitable for potential further thin film fabrication. The as made ethanol-based solution tends to precipitate fast but has been proven able to be stabilized by proper heat treatment. After calcination at $750-850^{\circ} \mathrm{C}$, perovskite phases successfully formed for all compositions with particle sizes of about $100 \mathrm{~nm}$. This sol-gel method provides an alternative to the conventional solid-state route, and is able to reduce the particle size by 3-4 times into the nano range. The method reported in this paper can be used to fabricate nanomaterials such as KNBNNO to assist advanced fundamental and practical investigations in future research.

\subsection{Data availability}

All relevant data that are not given in the paper can be obtained from the authors upon reasonable request.

Acknowledgements $\mathrm{VAB}$ would like to acknowledge the financial support from Erasmus Key Actions (agreement number 2018-1-FI01KA107-046769). VAB would also like to thank Dr. Elena Krivoshapkina for discussions of synthesis improvement. ZZ, MP, and AF acknowledge the Institute of Mineralogy of Leibniz University Hannover for the use of their equipment. The authors thank 
Dr. Valeriy Petrov for the discussions of XRD characterization and Dr. Tuomo Siponkoski for the measurements of particle size and zeta potential. YB acknowledges the joint funding by the University of Oulu and Academy of Finland profiling action "Ubiquitous wireless sensor systems" (grant number 24302332), and the Centre for Material Analysis of the University of Oulu for the use of their facilities. Open access funding provided by University of Oulu including Oulu University Hospital.

Author contributions VAB, ZZ, and MP carried out the experimental works. All authors co-wrote the paper.

\section{Compliance with ethical standards}

Conflict of interest The authors declare that they have no conflict of interest.

Publisher's note Springer Nature remains neutral with regard to jurisdictional claims in published maps and institutional affiliations.

Open Access This article is licensed under a Creative Commons Attribution 4.0 International License, which permits use, sharing, adaptation, distribution and reproduction in any medium or format, as long as you give appropriate credit to the original author(s) and the source, provide a link to the Creative Commons license, and indicate if changes were made. The images or other third party material in this article are included in the article's Creative Commons license, unless indicated otherwise in a credit line to the material. If material is not included in the article's Creative Commons license and your intended use is not permitted by statutory regulation or exceeds the permitted use, you will need to obtain permission directly from the copyright holder. To view a copy of this license, visit http://creativecommons. org/licenses/by/4.0/.

\section{References}

1. Damjanovic D (1998) Ferroelectric, dielectric and piezoelectric properties of ferroelectric thin films and ceramics. Rep Prog Phys 61:1267-1324

2. Bai Y, Jantunen H, Juuti J (2019) Ferroelectric oxides for solar energy conversion, multi-source energy harvesting/sensing, and opto-ferroelectric applications. ChemSusChem 12:2540-2549

3. Paillard C, Bai X, Infante IC, Guennou M, Geneste G, Alexe M, Kreisel J, Dkhil B (2016) Photovoltaics with ferroelectrics: current status and beyond. Adv Mater 28:5153-5168

4. Yang M, Luo Z, Kim DJ, Alexe M (2017) Bulk photovoltaic effect in monodomain $\mathrm{BiFeO}_{3}$ thin films. Appl Phys Lett 110:183902

5. Fridkin VM (1979) Photoferroelectrics. Springer, Berlin

6. Lopez-Varo P, Bertoluzzi L, Bisquert J, Alexe M, Coll M, Huang J, Antonio Jimenez-Tejada J, Kirchartz T, Nechache R, Rosei F, Yuan Y (2016) Physical aspects of ferroelectric semiconductors for photovoltaic solar energy conversion. Phys Rep Rev Sec Phys Lett 653:1-40

7. Grinberg I, West DV, Torres M, Gou G, Stein DM, Wu L, Chen G, Gallo EM, Akbashev AR, Davies PK, Spanier JE, Rappe AM
(2013) Perovskite oxides for visible-light-absorbing ferroelectric and photovoltaic materials. Nature 503:509-512

8. Bai Y, Siponkoski T, Peräntie J, Jantunen H, Juuti J (2017) Ferroelectric, pyroelectric, and piezoelectric properties of a photovoltaic perovskite oxide. Appl Phys Lett 110:063903

9. Bai Y, Tofel P, Palosaari J, Jantunen H, Juuti J (2017) A game changer: a multifunctional perovskite exhibiting giant ferroelectricity and narrow bandgap with potential application in a truly monolithic multienergy harvester or sensor. Adv Mater 29:1700767

10. Roedel J, Jo W, Seifert KTP, Anton E, Granzow T, Damjanovic D (2009) Perspective on the development of lead-free piezoceramics. J Am Ceram Soc 92:1153-1177

11. Wu J, Xiao D, Zhu J (2015) Potassium-sodium niobate lead-free piezoelectric materials: past, present, and future of phase boundaries. Chem Rev 115:2559-2595

12. Zheng T, Wu J, Xiao D, Zhu J (2018) Recent development in lead-free perovskite piezoelectric bulk materials. Prog Mater Sci 98:552-624

13. Bai Y, Vats G, Seidel J, Jantunen H, Juuti J (2018) Boosting photovoltaic output of ferroelectric ceramics by optoelectric control of domains. Adv Mater 30:1803821

14. Bai Y, Jantunen H, Juuti J (2018) Energy harvesting research: the road from single source to multisource. Adv Mater 30:1707271

15. Zheng F, Xin Y, Huang YW, Zhang J, Wang X, Shen M, Dong W, Fang L, Bai Y, Shen X, Hao J (2014) Above 1\% efficiency of a ferroelectric solar cell based on the $\mathrm{Pb}(\mathrm{Zr}, \mathrm{Ti}) \mathrm{O}-3$ film. J Mater Chem A 2:1363-1368

16. Yu Q, Li J, Sun W, Zhou Z, Xu Y, Xie Z, Lai F, Wang Q (2013) Electrical properties of $\mathrm{K} 0.5 \mathrm{Na} 0.5 \mathrm{NbO} 3$ thin films grown on $\mathrm{Nb}$ : $\mathrm{SrTiO} 3$ single-crystalline substrates with different crystallographic orientations. J Appl Phys 113:024101

17. Yu Q, Zhu F, Cheng L, Wang K, Li J (2014) Determination of crystallographic orientation of lead-free piezoelectric $(\mathrm{K}, \mathrm{Na})$ NbO3 epitaxial thin films grown on SrTiO3 (100) surfaces. Appl Phys Lett 104:102902

18. Luo J, Sun W, Zhou Z, Bai Y, Wang ZJ, Tian G, Chen D, Gao X, Zhu F, Li J (2017) Domain evolution and piezoelectric response across thermotropic phase boundary in $(\mathrm{K}, \mathrm{Na}) \mathrm{NbO} 3$-based epitaxial thin films. ACS Appl Mater Interfaces 9:13315-13322

19. Luo W, Sun W, Zhou Z, Lee H, Wang K, Zhu F, Bai Y, Wang ZJ, Li J (2017) Monoclinic (K,Na)NbO3 ferroelectric phase in epitaxial films. Adv Electron Mater 3:1700226

20. Zhai X, Wang S, Shang C, Yang P (2019) Chemical solution deposition as a route to narrow-band gap and room-temperature ferromagnetic perovskite [K0.5Na0.5NbO3] $(1-\mathrm{x})[\mathrm{BaNi} 0.5 \mathrm{Nb} 0$. 5O3-delta](x) films. J Mater Res 34:3627-3635

21. Birol H, Damjanovic D, Setter N (2006) Preparation and characterization of $(\mathrm{K} 0.5 \mathrm{Na} 0.5) \mathrm{NbO} 3$ ceramics. J Eur Ceram Soc 26:861-866

22. Bai Y, Xiang H, Jantunen H, Juuti J (2019) Multi-functional perovskites - an investigation of compositional and processing influence on microstructure, dielectric and ferroelectric properties. Eur Phys J Spec Top 228:1555-1573

23. Patterson A (1939) The Scherrer formula for X-ray particle size determination. Phys Rev 56:978

24. Wang F, Grinberg I, Jiang L, Young SM, Davies PK, Rappe AM (2015) Materials design of visible-light ferroelectric photovoltaics from first principles. Ferroelectrics 483:1-12 